\title{
REDES VIRTUAIS DE GOVERNANÇA AMBIENTAL: ANÁLISE DE UMA WEBSPHERE AMBIENTAL A PARTIR DA CIDADE DE CURITIBA ${ }^{1}$
}

\section{Virtual Networks of Environmental Governance: analysis of an environmental Websphere from the city of Curitiba}

Altair Rosa*

Klaus Frey**

Mario Procopiuck***

\section{Resumo}

O presente artigo tem como objetivo identificar o surgimento de redes de governança ambiental a partir da cidade de Curitiba e averiguar indícios de inserção num espaço global aberto pela Internet, como meios de busca da sustentabilidade local. Recorrendo às metodologias da análise de redes sociais e de análise de hyperlinks, busca mapear e analisar as estruturas relacionais existentes no ciberespaço entre atores envolvidos na política ambiental em Curitiba, demonstrando sua inserção numa Websphere ambiental global. Apresenta uma discussão teórico-conceitual

* Professor da Faculdade Pequeno Príncipe - Curso Biomedicina e Enfermagem; Assessor de Meio Ambiente do Serviço Social Autônomo - ECOPARANÁ; Engenheiro Ambiental, Mestre em Gestão Urbana pela PUC-PR. Email: altairrosa@yahoo.com.br

** Professor titular da PUC-PR; Doutor em Ciências Sociais e Mestre em Ciências da Administração (Diplom-Verwaltungswissenschaftler) pela Universität Konstanz, U.KN., Alemanha; Pós-Doutorado na Universidade Tecnológica de Berlim no. Email: klaus.frey@pucpr.br

*** Analista Judiciário - Administrador dos quadros da Justiça Federal de Primeiro Grau no Paraná; mestrado em Gestão Urbana - PUC-PR; doutorado em Administração - PUC-PR. Email: mario.p@ pucpr.br 
sobre governança ambiental, a abordagem metodológica para delimitação e mapeamento das redes organizacionais na Internet, bem como o próprio mapeamento das redes de governança ambiental. Demonstra a crescente relevância da formação de redes sociotécnicas de governança ambiental, apoiadas por TICs e da Internet como fator importante para promover visibilidade pública e fortalecer os laços e práticas interativas entre os mais diversos agentes envolvidos na política ambiental local.

Palavras-chave: Governança ambiental. Sustentabilidade local. Análise de redes sociais. Análise de hyperlinks.

\section{Abstract}

The present article aims to identify the emergence of an environmental network governance in the city of Curitiba and to verify evidences of its insertion in an open global Internet sphere as a mechanism for seeking local sustainability. The relational ties in the virtual space of the Internet between actors involved in environmental politics in Curitiba has been mapped and analyzed by using the methodologies of social network and hyperlink analysis, stressing its insertion in a global environmental Websphere. The article presents a theoretical discussion on environmental governance, the methodological approach for delimitating and mappingorganizational virtual networks, as well as the mappingof an environmental governance network of Curitiba itself. It demonstrates the growing relevance of ICT-supported environmental governance networks for promoting public visibility and strengthening interactive practices and ties amongst a multiplicity of agents involved in local environmental politics.

Keywords: Environmental Governance. Local Sustainability. Social Network Analysis. Hyperlink Analysis.

\section{INTRODUÇÃO}

O resgate da importância do município na definição e condução de políticas públicas e na gestão do território está, cada vez mais, exigindo a concepção 
de novas formas de intervenção voltadas ao atendimento das necessidades locais, assim como a incorporação de uma multiplicidade de novos atores na articulação dos interesses da comunidade. A qualidade da gestão local passa a depender da capacidade de obtenção de equilíbrios dinâmicos nas articulações entre atores internos, integrantes do próprio poder público, e externos, oriundos da iniciativa privada ou da sociedade em geral, participando da concepção e implementação de políticas públicas.

Além destas condicionantes relacionais que aumentam a complexidade da governança local, há de se considerar o fato de que a dinâmica tecnológica mundial das últimas décadas tem alterado o predomínio de tecnologias intensivas em capital para novas tecnologias intensivas em informação. Esta nova revolução tecnológica está afetando as formas tradicionais de relacionamento e funcionamento de todos os setores sociais, embora de forma desigual. As mudanças institucionais, econômicas e sociais, convergindo para a construção da chamada sociedade em rede (CASTELLS, 1999), exigem estratégias cooperativas capazes de mobilizar o capital social local e supralocal, ou seja, as competências e o conhecimento acumulados na sociedade, em favor de um desenvolvimento local mais sustentável.

Nesse contexto, o presente artigo tem por objetivo, a partir de uma pesquisa empírica das estruturas relacionais entre instituições ambientais presentes no ciberespaço, contribuir para uma melhor compreensão de práticas de governança ambiental urbana e de redes como elementos com significativas potencialidades para articulação de ações interinstitucionais; apresentar uma abordagem teórico-metodológica para identificar, visualizar e analisar as novas configurações de redes sociotécnicas; e, finalmente, apresentar e analisar uma rede de atores de governança ambiental com base na cidade de Curitiba, ressaltando as relações entre organizações do setor público, do setor privado e do terceiro setor com relevância para a governança ambiental da cidade.

\section{Meio Ambiente e Novas Estratégias de Atuação em Redes de Governança}

A questão ambiental representa tradicionalmente um desafio peculiar para a gestão pública por seu caráter interdisciplinar e interinstitucional que exige 
uma reorganização e reestruturação dos sistemas e das práticas políticas e administrativas, além de demandar novos padrões de participação proativa, sendo visto como fundamental no avanço em relação à sustentabilidade. Em grande parte dos documentos e publicações sobre desenvolvimento sustentável a dimensão da participação e a necessidade de aprofundamento das práticas democráticas têm ganhado destaque (FREY, 2001).

Os termos redes e parcerias têm sido crescentemente utilizados e difundidos na literatura e na prática da gestão local, buscando caracterizar o que seria um novo modelo de relações entre as várias organizações da sociedade: governos, empresas privadas, agências multilaterais, organizações não-governamentais, fundações, igrejas, sindicatos, entidades assistenciais. Sua virtude viria do fato de enfatizar a atuação motivada por interesses comuns, ao invés de relacionamentos pautados pelo conflito de interesse e pela concorrência. Cooperação e parceria têm sido apregoadas tanto como uma necessidade quanto como um modo de atuação e, ainda, como um valor em si mesmo (VALARELLI, 1999; ADULIS, 2002). Os mesmos conceitos também aparecem como possíveis soluções para resolver conflitos ambientais, como é o caso da Agenda 21 (GUTBERLET e GUIMARÃES, 1999), que poderia vir a ser uma ferramenta de governança local; baseada numa verdadeira rede de parcerias e colaboração, desde o nível local até o nível global, intercalando atividades e provendo um crescimento mais ordenado em conformidade com os princípios do desenvolvimento sustentável.

As redes como meio de articulação entre parceiros, além de representarem uma concepção analítica, podem ser entendidas como uma estratégia de gestão de políticas públicas e de enfrentamento de problemas complexos. Em princípio, rede significa parcerias com potencial de articular pessoas, famílias, grupos, organizações públicas e/ou privadas, nações. Pode, portanto, envolver e promover relações interpessoais, interorganizacionais e intersetoriais (INOJOSA, 1998) que se fazem necessárias na busca do desenvolvimento sustentável.

Reconhecendo as novas potencialidades relacionadas à ampliação dos atores sociais envolvidos na gestão da coisa pública, a literatura sobre gestão pública vem crescentemente enfatizando o tema de governança, salientando 
novas tendências de administração pública e de gestão de políticas públicas, particularmente a necessidade de mobilizar todo conhecimento disponível na sociedade em benefício da melhoria da performance administrativa e da democratização dos processos decisórios locais. As reformas administrativas levadas a cabo em muitos países e, inclusive, no Brasil, tanto pela vertente gerencial da chamada nova administração pública como pela vertente de gestão democrático-participativa, evidenciam uma nova compreensão de gestão pública e o reconhecimento da importância central de uma gestão consciente das interações, das relações sociais e dos fluxos de informação (FREY, 2002 e 2004).

Enquanto, do ponto de vista governamental a governança pública parece nascida da simples necessidade, como uma estratégia de "governar através de redes" (GOLDSMITH \& EGGERS, 2004), observa-se, paralelamente, que a população, a sociedade civil e as comunidades locais procuram aumentar sua influência na política local, reivindicando seus direitos e se engajando em tais arranjos participativos e de governança. Em virtude do potencial ambivalente e contraditório da configuração de rede no âmbito das políticas públicas em, de um lado, fomentar a capacidade para a ação coletiva, promover a identidade coletiva e estruturas mais horizontalizadas e, por isso, supostamente mais democráticas, mas de outro lado, provocar novas formas de exclusão social daqueles setores sem possibilidades de acesso aos novos arranjos institucionais, tornase fundamental o desenvolvimento de novas abordagens metodológicas capazes de analisar e compreender os processos de transformação e reestruturação do processo político em curso, sobretudo no que diz respeito à sua contribuição para a eficiência e eficácia como também a democratização e transparência das políticas públicas.

\section{Redes sociotécnicas de governança urbana}

Segundo Stephen Graham (1996), as duas características mais significativas que definem a civilização contemporânea são os saltos rumo a um planeta mais urbanizado e uma sociedade com crescente dependência da rapidez dos fluxos eletrônicos de informação. A maioria das mudanças contemporâneas parece estar relacionada à aplicação de redes 'telemáticas' 
e, à medida que o mundo se torna crescentemente mais urbanizado, estas redes vão penetrando em todas as áreas da vida urbana. As barreiras espaciais estão se reordenando e as limitações de tempo e espaço entre e dentro das cidades estão se modificando. Alguns lugares muito distantes são interligados quase que instantaneamente e as cidades se tornam cada vez mais dependentes de redes de comunicação humana, fluxos de serviços e mídia, fluxos de força de trabalho baseados no 'teletrabalho', e fluxos de dinheiro eletrônico.

Conforme a percepção de Manuel Castells (1999), é possível caracterizar a sociedade contemporânea, pelo menos nos países econômica e tecnologicamente mais avançados, como sociedade em rede por ela ser progressivamente caracterizada pela predominância da forma organizacional reticular em todos os campos da vida social. Nos últimos anos as redes tornaram-se foco de atenção das mais variadas áreas de conhecimento, ao passo que as telecomunicações, sobretudo a Internet, se tornaram poderosas ferramentas de comunicação, dando suporte tecnológico às emergentes redes sociais.

Enfatizando a importância da relação entre as novas redes comunicacionais com a necessidade de dinamização das relações sociais, Frey (2005) argumenta que as tecnologias da informação e comunicação (TICs) representam um potencial significativo para o fortalecimento de redes comunitárias ou sociais. As próprias comunidades virtuais, envolvendo pessoas e grupos de pessoas que, compartilhando interesses e afinidades comuns, encontram-se separadas pela distância física, representam, no contexto contemporâneo de um mundo cada vez mais dinâmico e complexo, novas possibilidades de aumento de cooperação e ação coletiva, bem como novas oportunidades para os integrantes de tais grupos buscarem seus interesses individuais e coletivos de forma efetiva, com menor dependência dos tradicionais valores e normas morais e éticas que caracterizaram as comunidades tradicionais.

Da articulação das redes sociais mediada pelas TICs emerge, pois, o conceito de redes sociotécnicas. Nesse relacionamento entre as dimensões sociais e tecnológicas, se partirmos do pressuposto que o avanço do padrão organizacional da rede, seguindo a concepção de Castells, está condicionado 
ao avanço tecnológico nas organizações e na sociedade, como também à distribuição espacial da infra-estrutura de telecomunicação(Graham, 1996), é para se supor que estes processos se dão em velocidades variadas e de forma desigual, beneficiando primordialmente os setores tecnologicamente integrados em detrimento dos setores que se encontram à margem destes crescentes fluxos de informação e conhecimento. Enquanto é inegável a sensação geral de uma maior aceleração do tempo proporcionada pela tecnologia, são ainda escassos os conhecimentos sobre as particularidades das alterações nas relações sociais dos diferentes campos da vida social e política.

Esse novo modelo emergente das redes sociotécnicas, caracterizadas pela instantaneidade das comunicações interativas entre pessoas e organizações geograficamente distantes, culminou por alterar a geometria pela qual as interações sociais acontecem. As redes sociotécnicas extrapolam o âmbito local para articular, compartilhar e intercambiar informações e recursos em nível regional, nacional e internacional. Nesse novo ambiente em permanente evolução e permeado pelas TICs, em que o espaço virtual tende a superar o espaço físico, estão emergindo novos padrões de relações sociais, econômicas e culturais entre indivíduos e organizações.

As redes de governança ou de políticas públicas locais, reconfiguradas com apoio das TICs, ao dinamizar seus fluxos internos, representam novas possibilidades de fortalecimento de laços locais das redes, ao mesmo tempo em que permitem e facilitam o acesso a redes nacionais ou globais enquanto fontes de informações e de potenciais recursos, bem como a prospecção enquanto coletivo identitário e de ação no espaço de articulações globais, ou como Milton Santos (2002) prefere dizer: nos "espaços da globalização, espaços mundializados reunidos por redes” (p.333).

Aplicada a nossa análise de redes sociotécnicas, isto significa que podemos interpretar as tramas dos hyperlinks como expressões, mesmo que parciais, desta busca consciente de produção de uma nova configuração espacial, de um novo espaço de coordenação social, construído a partir de processos de seleção, separação e exclusão, representando vontades e valorizações coletivas fundadoras de novas relações, cuja análise, no entanto, exige novas abordagens metodológicas inovadoras. 


\section{Metodologia de Análise de Redes Sociotécnicas ${ }^{2}$}

De fato, em nossa pesquisa sobre redes sociotécnicas na gestão urbana pretendemos analisar, de um lado, objetos ou artefatos tecnológicos, especificamente os Hyperlinks que, a princípio, representam uma intencionalidade instrumental embutida na suas funcionalidades técnicas e, de outro, inter-relações sociais resultantes de contingências sociais geradoras de uma dinâmica social que, por sua vez, é crescentemente condicionada pela morfologia tecnológica. Estamos, portanto, na busca da captação desta fluidez contemporânea (SANTOS, 2002, p.274) que, sendo ela essencialmente de caráter social, é baseada em redes técnicas que condicionam, limitam e, simultaneamente, ampliam possibilidades de interação social.

Interpretamos nesta pesquisa a rede de hyperlinks - a parte técnica das redes sociotécnicas - como resultado primordial da dinâmica social, baseada no princípio da volicionalidade, expressando, portanto, intencionalidades dos atores locais na definição de novas relações sociais apoiadas pelas novas tecnologias, mais especificamente, pelos hyperlinks e sites da Internet. Mesmo reconhecendo a condição facilitadora e, de forma simultânea, restritiva da tecnologia em si, a estrutura ou "arquitetura" dos hyperlinks - em constante transformação - representa um processo de contínua apropriação social desta tecnologia e, com isso, dinamização da vida cotidiana no local, pelas vivências e preocupações presentes no dia-adia dos atores locais ou supralocais, por seus julgamentos ou expectativas no que tange à possível contribuição de novas inter-relações para suas práticas cotidianas, por exemplo, no âmbito da gestão democrática de uma cidade.

Park, Barnett e Yong (2002) tratam da análise dos hyperlinks como elementos simbólicos que representam as relações entre atores que se interconectam na Internet. Nessa abordagem a Internet é vista como um sistema de hyperlinks que tem levado as organizações a utilizarem os Sites como extensão e representativas de suas relações sociais, especificamente como meios de contato com outras organizações ou pessoas, em tese, de qualquer parte do mundo. Por meio dos hyperlinks elas podem se conectar formando conjuntos nos quais informações podem ser intercambiadas, 
relações cooperativas mantidas, além de eles poderem servir de meio de comunicação para a realização de ações sociais conjuntas dentro de contextos e em torno de interesses ou projetos comuns.

Podemos, portanto, compreender as tramas de relações como base material de uma emergente esfera pública virtual, à medida que constitui um espaço aberto de comunicação e de troca informacional e argumentativa, capaz de dar suporte a processos políticos e ações coletivas, seja em benefício da mobilização social, seja em benefício da organização política. Representam, portanto, um potencial de suporte à gestão democrática de cidade. Neste caso peculiar, esta esfera pública virtual, com projeção para o espaço global virtual, pode auxiliar no aprimoramento de ações coletivas de redes sociotécnicas territoriais locais.

\section{Procedimentos metodológicos}

O principal enfoque do presente trabalho foi um levantamento das organizações ambientais de Curitiba, suas relações e a possível formação de redes de comunicação e troca de experiências e informações. E ainda, apresentar, para discussão, algumas reflexões sobre a rede de governança ambiental e as oportunidades e limites de sua expansão, desde a territorialidade local para o espaço global com apoio da Internet.

Em um primeiro momento foi escolhido o Site http://www. ambientebrasil.com.br/como janela de entrada para o inicio das pesquisas, por ser um portal rico em informações sobre organizações ambientais atuantes no Brasil, além de ter sua sede na cidade de Curitiba.

Para a formação da rede de governança ambiental, que se origina no município de Curitiba, foram observadas e pesquisadas as estruturas e características relacionais dos principais atores (instituições) que atenderam às exigências metodológicas abaixo descritas. As informações referentes aos atores envolvidos na pesquisa foram levantadas por meio de visitação de seus respectivos Sites.

As seguintes etapas foram necessárias para a realização da pesquisa:

1. Levantamento dos movimentos, organizações, associações, ONGs e redes ambientais com atuação na cidade de Curitiba. A partir 
das 50 primeiras instituições levantadas no Site www.ambientebrasil. com.br, foram adotadas critérios de corte com o objetivo de restringir a rede aos atores efetivamente envolvidos na governança ambiental da cidade, conforme os critérios que seguem:

- A instituição deve ter um Site institucional ativo na Internet.

- A instituição deve ter sede na cidade de Curitiba.

- Suas ações deveriam ser necessariamente voltadas para questões ambientais e, ainda, envolver ações ou projetos com relevância para o município de Curitiba; independente se sua atuação principal estiver direcionada para o âmbito local (Curitiba), estadual (Paraná), nacional ou internacional.

- As ações ambientais deveriam envolver necessariamente questões relacionadas com o meio urbano.

Depois de aplicados estes critérios restaram somente 19 instituições iniciais.

2. A partir da visitação dos Sites das 19 instituições catalogadas, passou-se, baseada na técnica Bola de Neve, ao reconhecimento e caracterização das articulações institucionais com o objetivo inicial de designar o conjunto de atores nucleares, a partir do qual, diferentes redes seriam, na seqüência, formadas. Incluíram-se nesse grupo de atores nucleares as instituições relacionadas às 19 levantadas na fase anterior, as quais também atendessem aos mesmos critérios de corte da etapa 1 . Nesta fase surgiram mais 32 atores que corresponderem a estes critérios, chegando a 51 instituições nucleares, consideradas de maior relevância.

3. A partir da determinação destes atores nucleares passou-se à formação de diferentes redes, considerando os diferentes tipos de relações mantidas entre eles e com outras instituições citadas nos respectivos Sites institucionais e envolvidas na rede de governança ambiental da cidade. As relações das redes foram categorizadas conforme segue:

- existência de parcerias em ações e projetos; 
- existência de afinidades temáticas, ou seja, compartilhamento de propósitos relacionados às questões ambientais locais, não necessariamente concretizados em projetos conjuntos.

- existência de hyperlinks com outras instituições ambientais, não atuando necessariamente na rede de governança local de Curitiba.

4. Com o objetivo de explicitar a inserção geográfica da rede local de governança ambiental na Websphere ambiental global, foi formada uma rede de cidades que se projeta a partir da cidade de Curitiba, em função das instituições nucleares terem sua sede nesta cidade, para 0 mundo, considerando suas relações com e entre as cidades das sedes das demais instituições da websphere.

Todos os dados levantados foram armazenados em um banco de dados, desenvolvido em ACCESS ${ }^{\circledR}$, que serviu como base para a alimentação do software de Análise de Redes Sociais (UCINET) para extração de medidas relacionais e para representação gráfica, por meio do software NETDRAW, das redes sociotécnicas de governança ambiental. Com base nas informações divulgadas nos respectivos websites, foram levantados os atributos individuais de cada instituição, classificando as instituições por setor em que atuam.

\section{Estudo de caso: Analise estrutural das redes de governança ambiental de Curitiba}

Os atores que emergiram do procedimento de coleta de dados acima descrito foram classificados conforme o setor ao qual pertenciam, atribuindo cores diferentes para sua identificação nos grafos: setor público (1) em verde, setor privado (2) em azul, terceiro setor (3) em vermelho. Dentre as 51 instituições nucleares da rede do ciberespaço, foram identificados $12(23,5 \%)$ pertencentes ao setor público, $12(23,5 \%)$ ao setor privado e 27 (53\%) com vinculação ao terceiro setor. Na seqüência, serão apresentadas e discutidas as características das redes de parcerias em ações e projetos, de parceiros temáticos, a rede global e, finalmente, a rede das cidades com influência sobre a governança ambiental de Curitiba. 


\section{Redes de parcerias em ações e projetos}

Inicialmente, partindo dos 51 atores nucleares, foram levantados e representados graficamente os atores envolvidos em projetos e ações ambientais, desenvolvidos na cidade de Curitiba.

A figura 1 mostra que são poucas as instituições que apresentam projetos com os respectivos parceiros nos seus stes, com exceção da Sociedade de Pesquisa em Vida Selvagem e Educação Ambiental (SPVS), do Clube Paranaense de Montanhismo e do Instituto de Estudos Ambientais Mater Natura, todas elas pertencentes ao terceiro setor. Esse dado pode estar relacionado ao fato de efetivamente existirem poucos projetos nas demais instituições, ou que não existe uma preocupação com a sua divulgação nos websites institucionais.

Os três casos com maior presença se referem a organizações que não têm seu foco principal de atuação no meio urbano, mesmo desenvolvendo atividades e projetos relacionados à cidade de Curitiba. De acordo com os resultados obtidos, evidencia-se que grande parte dos projetos e ações são concernentes à educação ambiental. Sobressai, por outro lado, a falta de presença da Prefeitura Municipal de Curitiba, mencionada apenas por intermédio da Secretaria Municipal de Educação, sem que, em nenhuma circunstância, tenha havido referência à Secretaria Municipal do Meio Ambiente, o órgão responsável pela gestão e política ambiental do município.

Salienta-se ainda a presença de instituições de pesquisa como a PUCPR e a UFPR, órgãos federais como o IBAMA e o Fundo Nacional do Meio Ambiente (FNMA), enquanto não se vislumbra uma representação efetiva do setor privado na rede de governança ambiental.

$\mathrm{Na}$ análise das medidas estruturais, o estudo focou a análise da centralidade. A análise de redes sociais (ARS) diferencia dois tipos de centralidade: a centralidade out-degree que corresponde ao número de atores referenciados no websites institucional como parceiros em projeto; já a centralidade in-degree se relaciona ao número de referências recebidas por um determinado ator pelas demais instituições integrantes da rede. Enquanto o out-degree, de certo modo, reflete a disposição de uma organização em mostrar sua inserção na rede de atores, a medida do in- 


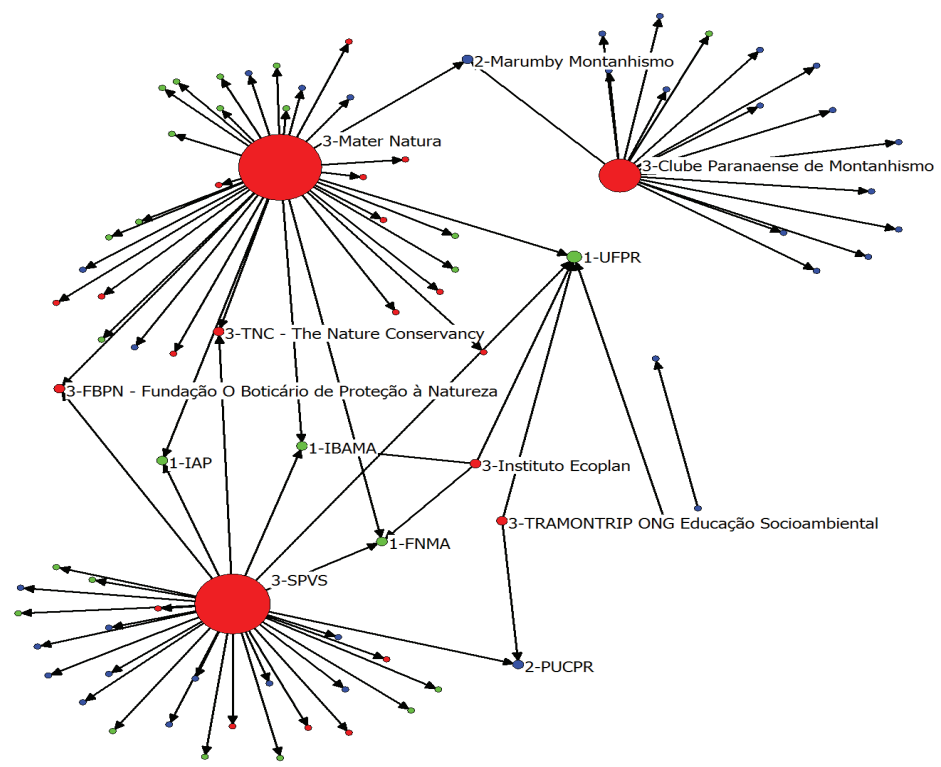

Figura 1: Redes de Parcerias em Ações e Projetos Virtual

degree mede o prestígio ou a popularidade de uma instituição entre os atores da rede (WASSERMAN e FAUST, 1994).

No caso da rede de projetos ambientais, apenas sete dos 117 atores identificados apresentam projetos referenciando os seus respectivos parceiros (out-degree). Os atores mais centrais, com maior out-degree, são: Mater Natura (40\%), SPVS (38\%) e o Clube Paranaense de Montanhismo (15\%). Nesta rede chama atenção a preponderância dos atores do Terceiro Setor com praticamente $98 \%$ das relações, ao passo que do setor público apenas a Secretaria Municipal de Educação se refere à parceria com a UFPR no projeto Separando Juntos na UFPR, apresentando com apenas uma referência um out-degree de $1 \%$. Também o setor privado é representado somente por uma organização.

Verificando o prestígio dos diferentes atores da rede, ou seja o número de referências recebidas pelas instituições, percebe-se inicialmente, 
que nenhuma das sete instituições mais centrais no quesito out-degree encontra-se entre as mais referenciadas pelos demais atores da rede. Isto significa que no âmbito dos projetos implementados, a articulação entre as organizações do terceiro setor tende a ser mínima, ao passo que são predominantes as relações com órgãos do Estado, empresas privadas e públicas ou fundações e organizações sociais criadas pelo Estado ou empresas. Elas são geralmente, as patrocinadoras de tais projetos, além das instituições de ensino e pesquisa que proporcionam suporte técnicocientífico aos projetos.

Dessa forma, aparece com maior in-degree a Universidade Federal do Paraná, seguida por órgãos públicos como o Fundo Nacional do Meio Ambiente (FNMA), o Instituto Ambiental do Paraná (IAP) e o Instituto Brasileiro de Meio Ambiente e de Recursos Naturais (IBAMA). Também, chama a atenção que a única prefeitura com mais de uma menção in-degree é a Prefeitura Municipal de Castro, enquanto a Prefeitura Municipal de Curitiba não foi lembrada nenhuma vez. Ela, no entanto, teve menções através de algumas secretarias, a exemplo da Secretaria Municipal de Educação como parceiro entre os projetos levantados. Na próxima parte, se aprofundarão as relações institucionais relativas aos projetos identificados.

\section{Rede de parceiros temáticos}

As parcerias temáticas, também constituídas a partir dos atores nucleares da política, expressam a constância de propósitos declarados, tanto em termos de missão quanto de objetivos, em relação à política ambiental na cidade de Curitiba. Percebe-se, mais uma vez, a predominância do terceiro setor também na rede de parceiros temáticos (figura 2), que abrange todas as instituições nucleares, as relações entre si e com demais organizações comprometidas com a causa ambiental, que no momento da pesquisa estavam referenciadas nos Websites dos atores nucleares como seus parceiros (sem estas parcerias serem necessariamente evidenciadas em projetos ou ações conjuntas). Apenas a Rede Verde de Informações Ambientais e o portal Ambiente Brasil aparecem como empresas privadas. Quanto a esta última organização, mesmo tendo adotado natureza jurídica de empresa privada, as suas formas de ação se assemelham muito mais às das organizações 
não-governamentais, além de representarem redes que integram em grande parte organizações da sociedade civil. Ainda, demonstram a crescente relevância de empresas privadas como prestadores de serviços também para as redes de organizações não-governamentais.

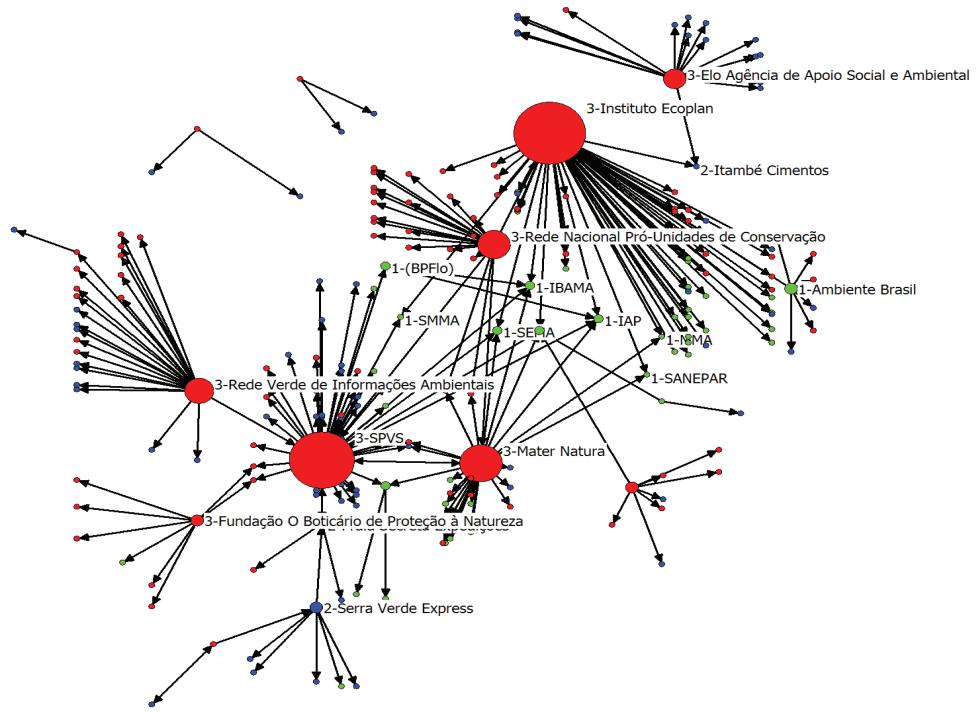

Figura 2: Rede Virtual de Parceiros Temáticos

Setor Público (1) O Setor Privado (2) OTerceiro Setor (3)

Na figura 2, dentre os 254 atores integrantes desta rede, há 16 (7\%) pertencentes ao setor público, seis (3\%) pertencentes ao setor privado e, claramente dominante, 232 (90\%) pertencentes ao Terceiro Setor. As instituições com maior centralidade na rede são: Instituto Ecoplan (23\% das relações), SPVS (20\%) Mater Natura (13\%), todas fazendo parte do terceiro setor e desenvolvendo ações relativas à educação ambiental e preservação de recursos naturais.

Comparando esta rede temática com a rede de projetos, é possível identificar um maior grau de densidade e de interconexões, indicando um 
grande potencial para cooperações espontâneas ou mobilizações específicas, mas também, para parcerias mais efetivas em projetos futuros.

Novamente, destaca-se a falta de organizações ambientais com ênfase nas questões do meio urbano; predominam, de um lado, organizações com foco na proteção da natureza em si e, de outro, organizações com ênfase na divulgação e intermediação de informações, desempenhando neste sentido, certamente, um papel fundamental no fortalecimento e na consolidação de uma green public sphere (TORGERSON, 1999), ou seja, um espaço de informação e comunicação compartilhado entre os stakeholders da questão ambiental, capaz de influenciar crescentemente, os processos de decisão política em acordo com seus objetivos "verdes" (FREY; ROSA, 2006: 44).

\section{Rede global}

Finalmente, foi delineada rede global (figura 4) que engloba as relações da rede de parcerias em ações e projetos, a rede de parceiros temáticos e a rede de hyperlinks. De fato, ela não difere substancialmente da rede de links, uma vez que, na questão ambiental parece existir uma prática intensiva de formação de redes pela trama de hyperlinks. A relativa riqueza desta websphere ambiental se deve certamente ao fato da existência de uma cultura organizacional no contexto do ambientalismo, inspirado fortemente no princípio da "teia da vida" (CAPRA, 1999). Aumentar de forma proativa a capacidade de agir coletivamente, inclusive de forma coesa e unida contra forças do campo político supostamente oposto, representa um dos princípios norteadores do próprio ambientalismo, ao passo que o poder público e os órgãos ambientais na administração pública ainda se mostram relutantes na publicação de suas parcerias (FREY; ROSA, 2006:46 ).

\section{Rede das cidades com influência sobre a governança ambiental de Curitiba}

A figura 5, que espelha a amplitude geográfica da distribuição dos atores relacionados à causa ambiental a partir de Curitiba, traz a representação gráfica das relações entre as 227 cidades que surgiram na análise da websphere ambiental global. São cidades que sediam as organizações que estão direta ou indiretamente envolvidas no sistema de governança 


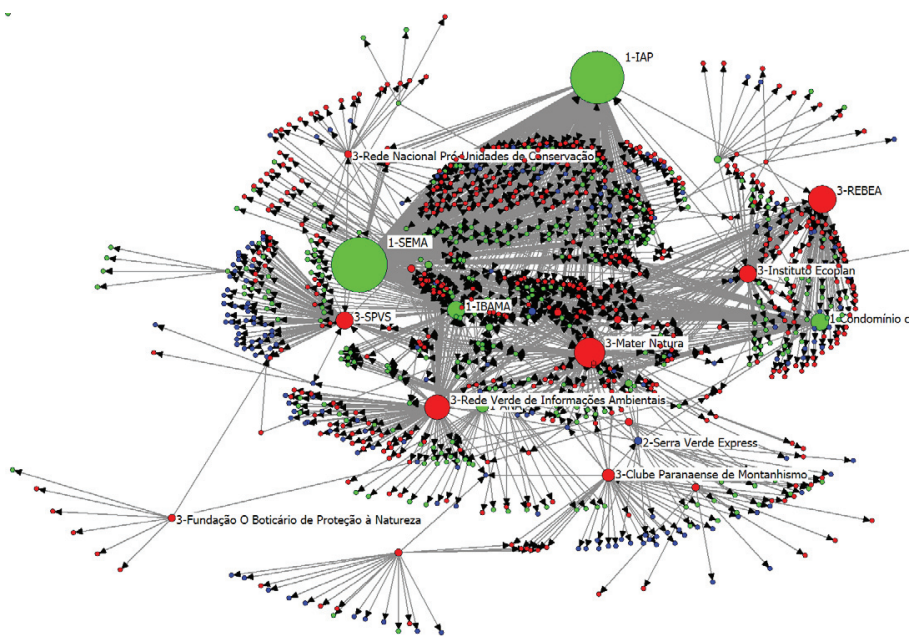

Figura 3: Rede Total da Análise da Internet

Setor Público (1) O Setor Privado (2) OTerceiro Setor (3)

ambiental de Curitiba. Pelo menos influenciam potencialmente sua dinâmica ao constarem como referências nos websites das instituições nucleares.

$\mathrm{Na}$ figura 5, a espessura dos enlaces é proporcional ao número de organizações que se relacionam entre cada par de cidades. Em função do método escolhido, tomando a cidade de Curitiba e seus atores nucleares como ponto de partida, ela aparece como cidade de maior destaque. $\mathrm{Na}$ verdade, a figura representa, de certa forma, a projeção da rede de governança ambiental de Curitiba na rede global de governança ambiental no ciberespaço.

A análise permite constatar que a maior parte da centralidade da cidade de Curitiba está relacionada com seu out-degree, o que era para se esperar, já que a cidade se constituiu no ponto de partida da pesquisa. Enquanto no quesito out-degree Curitiba reúne $72 \%$ de todos os enlaces possíveis, sua centralidade diminui significativamente para apenas 18\%, ao considerar apenas o in-degree, as referências recebidas. Se quiséssemos saber mais sobre a reputação da cidade de Curitiba e de suas instituições na rede ambiental global, seria necessário um estudo mais aprofundado 
para verificar quantos enlaces in-degree são oriundos de outros parceiros locais, da região de Curitiba, nacionais ou até internacionais.

Verificando os valores referentes ao in-degree, a mais importante medida para avaliar o prestígio dos atores na rede, ocupa posição de relevância Brasília, com 14\% de centralidade em função da localização dos principais Ministérios e Órgãos Federais de fomento nesta cidade. Merecem destaque também São Paulo e Rio de Janeiro, com 11\% e 9\%, respectivamente, onde está localizado o maior número de organizações não-governamentais ambientais no cenário nacional. No contexto internacional, emergiram como importantes centros de referência as cidades de Washington, com 3\%, e Nova York, com 2\%. A representatividade destas duas últimas cidades certamente está relacionada à importância das agências internacionais de fomento e de cooperação técnica internacional no financiamento de projetos ambientais nos países em desenvolvimento.

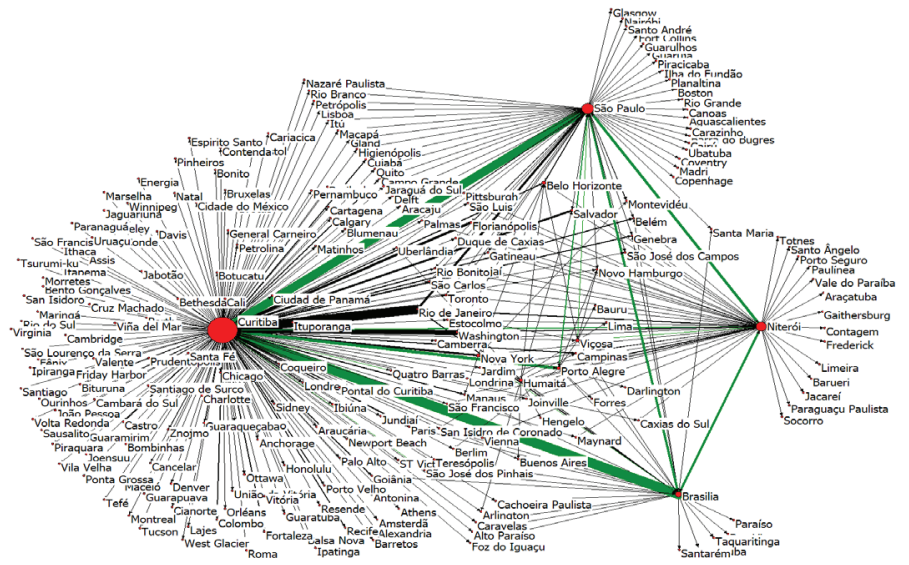

Figura 4: Rede de Cidades Envolvidas no Sistema de Governança Ambiental de Curitiba

\section{CONSIDERAÇÕES FINAIS}

Os governos ao redor do mundo estão buscando aprofundar as reformas da administração pública à medida que enfrentam pressões em virtude da elevação dos custos da máquina pública, do aumento das expectativas 
públicas e das demandas sociais, bem com de significativa perda de sua legitimidade democrática. A difusão das novas tecnologias da informação e comunicação no cotidiano do cidadão moderno coloca novos desafios aos governos no que diz respeito à modernização da administração pública e ao uso adequado e eficiente das tecnologias enquanto ferramentas capazes de dinamizar e estruturar sistemas de governança em prol do desenvolvimento sustentável.

O aspecto mais relevante na perspectiva da participação da sociedade civil não é tanto o entendimento dos movimentos como partes estruturadas ou estruturantes da realidade, mas, antes, seu papel nos processos de ação política, suas práticas sociais em construção, enquanto movimentos propriamente ditos (SCHERER-WARREN, 1993). Então, redes e parcerias se constituem em elementos fundamentais a serem considerados em processos de governança pública ou interativa (FREY, 2004) representam, pois, novas formas de governos buscarem integrar as partes interessadas nos processos de gestão e de políticas públicas e, simultaneamente, novas maneiras possíveis da sociedade civil tomar frente nas tomadas de decisões e nos processos da gestão da coisa pública.

Um dos objetivos principais desta pesquisa foi verificar até que ponto as transformações e ajustes ocorridos na administração pública, sobretudo no âmbito das políticas ambientais, se aproximam das concepções teóricas da governança interativa ou gestão em rede e, especificamente, até que ponto as TICs representam ferramenta de sustentação a tais práticas inovadoras de gestão.

Esta pesquisa sobre as redes em políticas ambientais - mesmo que parcialmente, pois se limita a representar relações no ciberespaço - demonstra o alto grau de integração e de cooperação que caracteriza este novo "movimento histórico, de transformación civilizatoria" (LEFF, 1992, p. 48) e multifacetado (VIOLA, 1996). A força que este movimento apresenta no âmbito internacional e global não encontra necessariamente sua correspondência no âmbito local das cidades. Pelo menos no que diz respeito às articulações identificadas no ciberespaço, quanto às políticas ambientais da cidade de Curitiba, foi possível perceber uma 
fraca representação de organizações ambientais locais com foco no meio urbano local, incluindo os órgãos ambientais do governo local.

Todavia, é importante ressaltar que a pesquisa abrangeu exclusivamente as estruturas de artefatos tecnológicos, as tramas de hyperlinks que representam apenas potencialidades virtuais de interação. Não é pelo fato de um ator citar outro em seu website ou simplesmente tê-lo como parceiro em um projeto que podemos inferir a existência de uma rede intensiva em interação, pois, por exemplo, pode ser bem restrita a troca efetiva de informações e precária a realização dos projetos e ações mencionados nos sites. Mesmo que o fato de ter incluído ou prestigiado outra instituição por meio de Hyperlink está baseado numa intencionalidade institucional, esta não garante comprometimento e interação efetiva. Tornam-se, portanto, necessárias investigações futuras junto aos principais atores, integrantes das redes sociotécnicas, para verificação do grau de aproveitamento destes novos canais técnicos de articulação no dia-a-dia da gestão ambiental local.

Face à complexidade que caracteriza o problema do desenvolvimento sustentável, a gestão da informação para a cidadania e o desenvolvimento sustentável (DOWBOR, 2005), a diversificação e o aprimoramento dos canais de participação e de deliberação política, a abertura dos órgãos do Estado para uma governança ambiental ampliada, bem como a recorrência a uma rede global de instituições e de conhecimento, são os principais desafios que podem ser mais bem enfrentados mediante o uso efetivo e democrático dos novos meios de informação e comunicação, colocando tais tecnologias a serviço de um novo modelo de cooperação e de parceria entre governo e sociedade (CAMARGO, 2003).

No atual contexto da sociedade da informação, as TICs podem ser aliado fundamental na busca de novos arranjos de governança e de soluções cooperativas para o desenvolvimento sustentável local.

A presente pesquisa, de cunho exploratório, por um lado, ao utilizarse dos hyperlinks que relacionam websites como unidades básicas de análise para explicitação de redes interorganizacionais locais e globais, alcançou uma amplitude geográfica dificilmente possível de ser obtida pelos meios tradicionais de coleta de dados, principalmente quando 
considerado os recursos que seriam necessários; por outro lado, por depender exclusivamente de informações expressas em websites evidencia restrições quanto às possibilidades de entender com maior profundidade 0 posicionamento de cada uma das organizações que emergiu em tais redes ou daquelas que, por algum motivo, não se utilizam da Internet para fazer visíveis suas ações relacionadas à política ambiental. Certamente, novas pesquisas serão necessárias para uma avaliação mais aprofundada das implicações do uso das tecnologias informacionais em políticas públicas ambientais.

\section{NOTAS}

1 Este trabalho está baseado em resultados das pesquisas "Redes técno-sociais e gestão democrática da cidade" (coordenação geral: Prof. Tamara Egler, IPPUR), que contou com auxílio financeiro do Registro Geral de Endereçamento da Internet, para América Latina e o Caribe - LACNIC, através do programa FRIDA, Fundo Regional para o desenvolvimento da Internet para a América Latina e o Caribe, disponível em http://programafrida.net/pt/, e "Governança e redes sociais na era digital" (coordenação: Prof. Klaus Frey) com auxílio financeiro do Conselho Nacional de Desenvolvimento Científico e Tecnológico (CNPq), bem como na dissertação de mestrado de Altair Rosa (2007). Uma versão preliminar deste trabalho foi apresentada no Encontro Anual da ANPUR de 2007 (Frey, Rosa 2007)

2 Referente à metodologia utilizada na pesquisa geral e, especificamente, na pesquisa sobre governança ambiental, encontram-se descrições e análises críticas mais aprofundadas em: Egler (2006), Kauchakje et al. (2006), Frey/Procopiuck (2007), Rosa (2007), Procopiuck (2007) e Procopiuck e Frey (2007).

\section{REFERÊNCIAS}

ADULIS, D. Da colaboração à parceria. 2002. Disponível em: < http://www.rits.org. br/redes> Acesso em: 28/05/2005.

CAMARGO, A. Governança para o século 21. In: TRIQUEIRO, A. (orgs.). Meio ambiente no século 21. Rio de Janeiro: Sextante, 2003.

CAPRA, F. A teia da vida, uma nova compreensão científica dos sistemas vivos. São Paulo: Cultrix, 1999.

CASTELLS, M. A sociedade em rede. (A era da informação, sociedade e cultura: v1). São Paulo: Paz e Terra, 1999. 
DOWBOR, L. Información para la ciudadanía y el desarrollo sustentable. Nueva Sociedad, Caracas, Venezuela, 2005.

EGLER, T. (org.) Redes técno-sociais e gestão democrática da cidade, FRIDA-Fundo Regional para a Inovação Digital na América Latina e Caribe, Rio de Janeiro, IPPUR/ UFRJ, 2006; disponível em: http://acd.ufrj.br/ interacao/login/login.php.

FREY, K.et al. O acesso à informação. In: Speck, B.W. (ed.) Caminhos da transparência. Análise dos componentes de um sistema nacional de integridade. Campinas: Unicamp, 2002.

FREY, K., ROSA, A. Redes sócio-técnicas nas políticas ambientais de Curitiba. In: Relatório parcial do grupo de Curitiba para projeto FRIDA. 2006.

FREY, K.; ROSA, A. Rede de governança ambiental e sustentabilidade local. In: XII Encontro Nacional da ANPUR, Anais... Belém, ANPUR, 2007, p. 1-21

FREY, K. A dimensão político-democrática nas teorias de desenvolvimento sustentável e suas implicações para a gestão local. Ambiente \& Sociedade, ano IV, n. 9, p.115$148,2^{\circ}$. Semestre de 2001.

FREY, K. Governança interativa: uma concepção para compreender a gestão pública participativa? Política \& Sociedade. Revista de Sociologia Política, v.1, n 5, 2004, p.117-136.

FREY, K. Governança urbana e redes técno-sociais: uma aproximação teóricometodológica. Trabalho apresentado no seminário "Redes tecnosociais e gestão democrática da cidade”, program Frida da Lacnic, Rio de Janeiro, IPPUR/UFRJ, 2006.

FREY, K.; PROCOPIUCK, M. Policy websphere analysis: Uma abordagem para se (re)pensar a transformação estrutural da esfera pública na era da Internet, Curitiba, 2007 (trabalho submetido à revista)

GOLDSMITH, S.; EGGERS, D. Governing by network. The new shape of the public sector. Washington D.C.: Brookings, 2004.

GRAHAM, S. Rumo à Cidade em Tempo Real - Desenvolvimento Urbano numa Sociedade Globalizada e Telemediática, 1996. Disponível em: < http://www.eesc. usp.br/nomads/tics_arq_urb/cidtempo.doc > Acesso em: 03/04/2008. 
GUTBERLET, J e GUIMARÃES C.V.P. Desenvolvimento sustentável e Agenda 21. Guia para sociedade civil, Municípios e empresas. Apostila 2. São Paulo: Fundação Konrad Adenauer, maio 2002..

INOJOSA, R. M. Intersetorialidade e a configuração de um paradigma organizacional. Revista de Administração Pública. Vol. 32, Rio de Janeiro, 1998.

KAUCHAKJE, S.; PENNA, M.C.; FREY, K.; DUARTE, F. Redes socio-técnicas y participación ciudadana: propuestas conceptuales y analíticas para el uso de las TICs. REDES- Revista hispana para el análisis de redes sociales, vol.11, n. 3, diciembre 2006; disponible em: http://revista-redes.rediris.es. Acesso em: 03/08/2007.

LEFF, E. Cultura democrática, gestión ambiental y desarollo sustentable em América Latina. Ecología Política. Cuadernos de Debate Internacional, n.4, Barcelona: FUHEM/CIP, ICARIA, 1992, p.47-55.

PARK, Han Woo; BARNETT, George A. e NAM, In Yong. Interorganizational Hyperlink Networks among Websites in South Korea. Networks and Communication Studies, v.16, n.3-4. p.155-174. 2002.

PROCOPIUCK, M.. Governança local e redes sociotécnicas de difusão social de TICs nas cidades de Porto Alegre e Curitiba. 2007. 237 p. (Dissertação de Mestrado). PPGTU - Programa de Pós-graduação em Gestão Urbana, Pontifícia Universidade Católica do Paraná, Curitiba.

PROCOPIUCK, M.; FREY, K. Redes sociotécnicas de difusão social de TICs em Porto Alegre e Curitiba. In: EnANPAD, 2007, Rio de Janeiro. Publicação Anais do evento, 2007.

ROSA, A. Rede de governança ambiental na cidade de Curitiba e o papel das tecnologias da informação e comunicação. 2007. (Dissertação de Mestrado). PPGTU - Programa de Pós-graduação em Gestão Urbana, Pontifícia Universidade Católica do Paraná, Curitiba.

SANTOS, M. (2002) A natureza do espaço. Técnica e tempo. Razão e emoção. São Paulo: EdUSP.

SCHERER - WARREN, I. Redes de movimentos sociais. São Paulo: Loyola, 1993.

TORGERSON, D. The promise of green politics. Environmentalism and the public sphere. Durham/London: Duke University Press, 1999. 
VALARELLI, L. L. Parcerias - noções gerais. In: Apoio à gestão. Rio de Janeiro.1999. Disponível em: < http://www.rits.org.br/redes > . Acesso em: 28/05/2005.

VIOLA, E. A multidimensionalidade da globalização, as novas forças sociais transnacionais e seu impacto na política ambiental no Brasil, 1989-1995. In: FERREIRA, L.C.; VIOLA, E. (orgs.) Incertezas de sustentabilidade na globalização. Campinas, SP: UNICAMP, 1996.

WASSERMAN, S e FAUST, K. Social network analysis: methods and applications. Cidade: Cambridge University Press, 1994. 